9-10-2019

\title{
An Examination of Traffic Volume during Snow Events in Northeast Ohio
}

Daniel Burow

Christopher Atkinson

University of North Dakota, christopher.atkinson@UND.edu

How does access to this work benefit you? Let us know!

Follow this and additional works at: https://commons.und.edu/geo-fac

\section{Recommended Citation}

Daniel Burow and Christopher Atkinson. "An Examination of Traffic Volume during Snow Events in Northeast Ohio" (2019). Geography \& Geographic Information Science Faculty Publications. 9.

https://commons.und.edu/geo-fac/9

This Article is brought to you for free and open access by the Department of Geography \& Geographic Information Science at UND Scholarly Commons. It has been accepted for inclusion in Geography \& Geographic Information Science Faculty Publications by an authorized administrator of UND Scholarly Commons. For more information, please contact und.commons@library.und.edu. 


\title{
An examination of traffic volume during snow events in northeast Ohio
}

\author{
Daniel Burow $^{1}$ D $\cdot$ Christopher Atkinson ${ }^{2}$
}

Received: 24 April 2019 / Accepted: 6 September 2019 / Published online: 10 September 2019

(c) Springer Nature B.V. 2019

\begin{abstract}
Snowfall presents a hazard to drivers by reducing visibility and increasing safe stopping distances. Some drivers cancel trips if snowfall is occurring or forecast, and traffic volumes often decrease on snowy days. Lake-effect snow is very localized and is thus hypothesized to have a lesser influence on traffic volume than synoptic-scale snow, which usually covers a broader areal extent. We analyze traffic volume in northeast Ohio during 25 snow events and use a matched-pair analysis to determine whether volumes differ between lake-effect and synoptic-scale snowfall in these regions. We also examine the rate at which traffic volume decreases during snow events by time of day and day of week. Results indicate that there is little difference in mean traffic volume decreases when comparing lake-effect and synoptic-scale snow. Hourly trends suggest that traffic volume is most sensitive to snowfall during the midday on weekdays and late afternoon on weekends and least sensitive to snowfall during the overnight hours. Findings presented herein can assist in transportation planning, risk analysis and roadway safety.
\end{abstract}

Keywords Traffic volume $\cdot$ Snow $\cdot$ Transportation $\cdot$ Great Lakes

\section{Introduction}

Adverse weather conditions can play a major role in traffic flow, volume and crash risk. The Federal Highway Administration (FHWA) reports annual means of over 210,000 traffic crashes and 700 fatalities occur during winter precipitation in the USA (FHWA 2015). A cautious driver is likely to reduce speed, increase following distance, decrease acceleration rate or even cancel his or her trip altogether during hazardous weather conditions (Rutty and Andrey 2014). Research on the effects of snowfall on traffic is useful to transportation officials who regularly monitor traffic flow for infrastructure planning and snow removal strategies (Crevier and Delage 2001). Numerical models have been designed to

Daniel Burow

daniel.burow@valpo.edu

1 Department of Geography, University of Tennessee, Knoxville, 1000 Phil Fulmer Way, Knoxville, TN 37996, USA

2 Department of Geography and GISc, University of North Dakota, 221 Centennial Drive, Stop 9020, Grand Forks, ND, USA 
forecast road conditions during inclement weather, and accurate quantification of traffic volume during snowfall improves their effectiveness (Crevier and Delage 2001). Researchers have sought to measure crash risk during inclement weather, which is difficult to accurately calculate unless the number of safe trips are known (Abdel-Aty and Pemmanaboina 2006; Mills et al. 2011; Black and Mote 2015). Since traffic volumes tend to decrease during adverse weather conditions, measures of the rate at which volume decreases during snowfall are helpful to researchers when comparing bad-weather to fair-weather crash risk.

Lake-effect snow is more localized than synoptic-scale snow (Bates et al. 1993), and drivers may not anticipate poor driving conditions on their trip. Some drivers may plan trips for fair weather and pleasant driving, only to encounter an intense lake-effect snow band, resulting in accidents (NBC Chicago 2014; Chicago Tribune 2015). The purpose of this study is to determine whether traffic volume varies in the same way during lake-effect snow as it does during synoptic-scale snow. We hypothesize that lake-effect snow will not decrease traffic volume as drastically as synoptic-scale snow systems since drivers may not anticipate driving into a localized lake-effect snow band.

\section{Background}

Travelers in snowy climates are likely to consult weather forecasts when planning their trips (Rutty and Andrey 2014; Barjenbruch et al. 2016) and may alter plans or even cancel their trips if snow falls (Kilpelainen and Summala 2007). The rate at which traffic volume decreases during snow events depends on several factors, including day of week and time of day (Datla and Sharma 2008). Observed decreases in volume include 3.8\% in Belgium (Cools et al. 2010), 7-17\% per centimeter of snowfall in Alberta (Datla and Sharma 2008), to as much as $22 \%$ during heavy snow (Maze et al. 2006). Weekend volumes are more susceptible to inclement weather conditions since trips are usually more cancellable (Al Hassan and Barker 1999; Datla and Sharma 2008; Cools et al. 2010). In a similar manner, truck volume decreases much less than smaller vehicles, likely because truck drivers operate on strict schedules and do not have flexibility to cancel trips for inclement weather (Call 2011; Roh et al. 2015).

Increased crash risk is a notable hazard during snow events (Medina et al. 2017). Twelve percent of crashes in Salt Lake County, Utah, occur during inclement conditions (Call et al. 2019), and that percentage may be higher in other parts of the country that receive more precipitation. Crash risks in major Canadian cities increase by over $50 \%$ during snowfall (Andrey 2010). Extreme examples of this include chain-reaction pileups, which often occur during hazardous driving conditions when visibility is limited. Pileups during winter weather involve more vehicles than pileups during other weather conditions (Call et al. 2018), suggesting that traffic volume was too high for drivers to maintain adequate stopping distance during these conditions.

Most studies on traffic volume and accidents during snowfall use a fairly coarse spatiotemporal scale (Eisenberg and Warner 2005) or examine areas that receive most of their annual snowfall from synoptic-scale snowstorms (Andrey et al. 2003; Datla and Sharma 2008; Zhang et al. 2013). These larger-scale storms usually cover large areas and are often easier to forecast and publicize. Lake-effect snow, on the other hand, is very localized. The exact location of snowfall during these events is dependent on fine-scale low-level wind patterns, which are difficult to measure and predict (Bates et al. 1993). These events often occur during dominant high-pressure regimes, so locations outside of the immediate 
snowfall band often experience clear skies (Ellis and Leathers 1996). Thus, travelers may not be aware of the possibility of hazardous conditions when driving or planning their trip. This subject has not been studied in great detail, and we seek to understand traffic volume disruption at a finer spatial and temporal scale.

\section{Methods}

\subsection{Study area}

Ohio is an ideal area for this study. Mean annual snowfall in the state ranges from $75 \mathrm{~cm}$ (30 inches) in northwest Ohio to over $250 \mathrm{~cm}$ (100 inches) in northeast Ohio due to the influence of nearby Lake Erie (Changnon et al. 2006). The Ohio Department of Transportation contracts to the firm MS2 for traffic data management. MS2 is a company that designs and hosts software for transportation analytics and is based on Ann Arbor, Michigan. There are 196 counters that continually monitor traffic volume on an hourly scale in Ohio. Most of these counters are located on highways, although a few are on minor arterial roads.

\subsection{Event identification of lake-effect snow}

National Weather Service daily weather observations from Cleveland, Ohio, were obtained for the months of December to March for the winters of 2011-2012, 2012-2013, 2013-2014 and 2014-2015. Climatologically, these months are the snowiest of the year in the Great Lakes region. Days with snowfall at KCLE were identified from these records and further classified as a possible lake-effect event by using a set of meteorological criteria.

The first criterion was sub-freezing temperatures throughout the day in question. Temperatures above freezing can lead to melting and freezing patterns throughout the day, freezing rain, mixed wintry precipitation, ice accumulation or other precipitation types that may affect driving conditions to a greater extent than pure snowfall. Since these other mixed precipitation types are beyond the scope of this research, days with high temperatures above freezing were excluded. While it is possible for snow to fall on days in which the high temperature was above freezing, we have a sufficient sample of sub-freezing days with precipitation and prioritized excluding days with the possibility of mixed precipitation types over further increasing sample size.

The second criterion for a lake-effect classification was low-level winds coming from the direction of Lake Erie. Minimal directional wind shear in the lower and mid-levels of the atmosphere is ideal to maintain lake-effect snowstorms (Niziol 1987). We visually examined the North American Regional Reanalysis (NARR) maintained by the National Oceanic and Atmospheric Administration (NOAA) for surface to 700 millibar winds over the study region from the north, northwest or west, since this would put the area downwind of Lake Erie and represent an ideal setup for lake-effect snow. Winds from the south or east at these levels are common when mid-latitude cyclones pass through the region, and we classified such days as synoptic-scale snow events.

The third criterion was a high snow-to-liquid ratio. Arctic air masses that induce lakeeffect snowfall commonly, though not always, make for lighter, fluffier snow with higher snow-to-liquid ratios. The warmth of the lake surface can lead to strong instability and 
rising motion in snowstorms with dendritic growth zones closer to ground level than is commonly found in synoptic-scale systems (Jiusto and Weickmann 1973). These factors combine for more efficient snow formation and minimal snowflake sublimation before reaching the surface, which produces high ratios that are evident in long-term snowto-liquid climatologies (Schmidlin et al. 1992; Baxter et al. 2005). We examined daily observations for a snow-to-liquid ratio of 15:1 or greater for lake-effect snow days.

If a given day's observations at Cleveland met these meteorological criteria, radar archives were consulted for imagery from the Cleveland (KCLE) radar. National radar composites are archived by the Iowa Environmental Mesonet and available through NOAA's National Centers for Environmental Information (NCEI). Typical lake-effect reflectivity patterns exhibit localized, but spatially continuous reflectivities originating from the direction of the lake and moving onshore. A key factor is that areas outside the lee of the lake did not receive snowfall during suspected lake-effect events-such a pattern would indicate that snowfall was originating from locations other than the Great Lakes. In the context of traffic flow, drivers coming from areas not in the lee of the lake may not anticipate lake-effect snowfall along their journey, so the location and areal extent of the snowfall with respect to the lake and wind direction were critical to classify an event as lake-effect in nature. An example of a typical lake-effect snowstorm is shown in Fig. 1a.

If the above criteria were met, the day was classified as a lake-effect snow event for the duration of snowfall in the study area on that given day. It is not uncommon for synoptic-scale snowfall (which does not meet the above criteria) to be enhanced in both intensity and areal coverage by lake instability near the shoreline. However, these specific events (a "lake-enhanced" synoptic event) were not classified as lake effect for the purposes of this study within the broader context of the research question: Drivers would be better aware of poor driving conditions for a synoptic event with broader areal coverage, even with some lake enhancement. Therefore, we excluded these lakeenhanced synoptic events from classification.

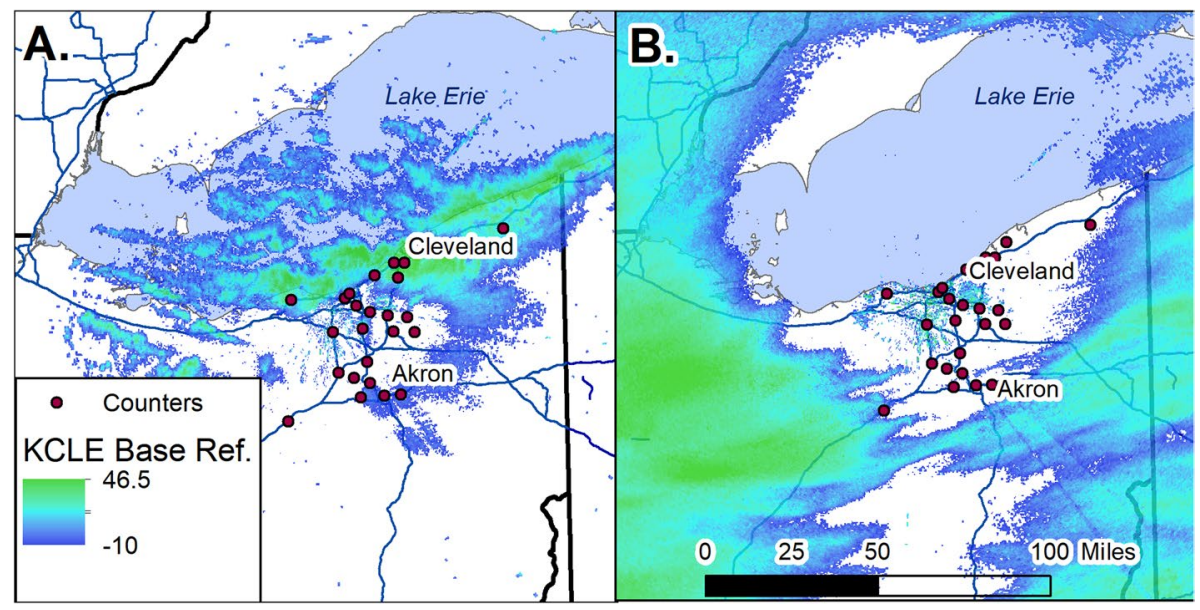

Fig. 1 Radar images of lake-effect (a) and synoptic-scale (b) snow events 


\subsection{Event identification of synoptic-scale snow}

Synoptic-scale snow events were classified using a similar system, albeit with less rigid meteorological criteria. Sub-freezing high temperatures were still required in synoptic events to avoid including days with mixed precipitation. Wind direction can vary somewhat with synoptic-scale snowfall, although strong snowfall tends to occur on the northwest side of a surface low, where low-level winds are usually from the northeast. The most important factor for identifying synoptic-scale snow in this study was the spatial pattern of radar and satellite imagery during each event, since clouds and radar reflectivity patterns exhibited broader areal extents and were not confined to the lee of the lake. Figure $1 \mathrm{~b}$ shows a common radar image from a synoptic-scale snow event.

\subsection{Classification results}

We used these classification strategies to produce two separate sets of lake-effect and synoptic snow events. If a given event was not easily and confidently classified one way or another, it was excluded. This approach yielded 23 lake-effect events and 20 synoptic events, from which 15 lake-effect and 10 synoptic-scale events were randomly selected for study. As in Call (2011), events from December 20th to January 2nd were not studied since traffic patterns and travel plans during the holiday season vary substantially from the typical workweek, leading to issues in controlling for such pattern changes.

\subsection{Radar}

For each selected event, radar data were obtained from NCEI's NEXRAD data inventory for the duration of the event, up to $24 \mathrm{~h}$. We used 1-h accumulated precipitation to estimate the locations at which snow was falling using the Weather Surveillance Radar-1988 Doppler Precipitation Processing System, which allows the precise location of snowfall to be mapped with the best possible accuracy since lake-effect snow events frequently occur between ground-based observation stations.

Disadvantages to using radar data to determine snowfall location relate to the height of the beam above ground level. A radar beam will increase in height above ground due to its own tilt and the curvature of Earth's surface as the beam moves further from the radar. However, all of the study area except for extreme northeast Ohio is within the 90-km radius of the KCLE radar suggested by Niziol (1987) to detect lake-effect snowfall at a sufficiently low beam height.

The inverse is also true: Low beams near the radar can detect non-meteorological objects that the radar still detects. This is commonly referred to as "ground clutter." We accounted for this by excluding sixteen traffic counters that were located within $8 \mathrm{~km}$ of the KCLE radar since reflectivities detected there may not be meteorological in nature.

\subsection{Traffic count procedure}

We obtained and overlaid 1-h accumulated precipitation radar data onto a map of the traffic counters in ArcGIS 10.4 (ESRI 2014) for each hour of each event selected by the above methodology to determine which locations received snowfall during the hour in question. Then we obtained hourly traffic volumes at each "snowy" counter from the MS2 database 
and compared them to volumes from a control period to account for daily traffic fluctuations due to rush hour, etc. Control periods were selected as the same hour of the same day of the week, exactly 1, 2 or 3 weeks before or after the given snowfall event. We preferably used control periods that were a week prior to the event, unless weather observation included precipitation or high temperatures below $0{ }^{\circ} \mathrm{F}$ as temperature has been shown to have a correlation with traffic volume (Al Hassan and Barker 1999; Cools et al. 2010). Once again, days from December 20th to January 2nd were not selected as control periods. If a control period from the previous week exhibited inclement weather, we used a control period on the same time of day the following week. If there was precipitation or sub-zero temperatures on that date as well, then we examined the date 2 weeks before the snow event, then 2 weeks after, etc., until a suitable control period was identified.

Traffic rates for each counter during every hour of each snowfall event were calculated by dividing the snow volume by the control volume. Thus, if a given counter reported a volume of 90 vehicles during a given snowy hour, and the same counter reported 100 vehicles during the selected control period, the rate at that counter would be 0.9 for that hour (90 vehicles/100 vehicles). We refer to this traffic volume rate as a traffic difference rate, abbreviated TDR. A TDR over 1.0 indicates that volume was higher during the snow event than during the control event. While not common, some TDRs over 1.0 were observed in the study. Lower TDRs were indicative of fewer vehicles on the road during snow events, suggesting that snowfall played a role in traffic volume disruption.

\section{Results and discussion}

\subsection{Lake-effect and synoptic rates}

Some counters were better sampled through the above methods than others because of the varying locations of selected snow events and varying degrees of traffic record completeness. We selected counters with at least 30 observations of TDRs during both lake-effect and synoptic-scale events for further analysis. To minimize spatial autocorrelation, we excluded three of these counters because they were located within three miles of another better-sampled counter. Thus, 23 counters were adequately spaced and sampled.

Table 1 shows the mean TDRs during lake-effect and synoptic-scale snow events for these 23 counters. Thirteen counters had higher mean synoptic TDRs than lake-effect TDRs, indicating synoptic-scale snow caused a bigger decrease in traffic volume, on average, at these locations. The other ten counters had higher lake-effect TDRs.

These results suggest that lake-effect traffic TDRs are not higher than synoptic TDRs, as hypothesized, since a slight majority of counters had lower lake-effect TDRs than synoptic TDRs. When totaled, the mean TDR is 0.894 for lake-effect snow and 0.900 for synoptic-scale snow. Figure 2 shows two boxplots of the variation in mean traffic volumes for each type of snow among the 23 counters. While driver awareness of conditions may vary from lake-effect events to synoptic-scale events, the effects on traffic volume are likely outweighed by other factors that could not be accounted for. These factors could include road type and use, as well as the intensity and timing of selected snow events. Most of the listed counters are located on high-capacity, high-speed roads, such as interstates and state highways, and we did not have adequate sampling of counters on more minor roads to perform an in-depth comparison of rates between road types. Meteorological and topographic variables such as land friction convergence and orographic lifting can affect snowfall intensity 
Table 1 Lake-effect and synoptic TDRs for well-sampled counters with the lower of the two rates bolded and italicized

\begin{tabular}{|c|c|c|c|c|c|c|}
\hline Counter ID & Road type & County & $\begin{array}{l}\text { Observations } \\
\text { during lake-effect } \\
\text { snow }\end{array}$ & $\begin{array}{l}\text { Mean } \\
\text { lake-effect } \\
\text { TDR }\end{array}$ & $\begin{array}{l}\text { Observations } \\
\text { during synoptic } \\
\text { snow }\end{array}$ & $\begin{array}{l}\text { Mean } \\
\text { synoptic } \\
\text { TDR }\end{array}$ \\
\hline 6604 & Minor arterial & Ashtabula & 41 & 0.936 & 61 & 0.942 \\
\hline 19885 & Interstate & Wayne & 53 & 0.886 & 78 & 0.846 \\
\hline 24843 & State highway & Lake & 99 & 0.870 & 74 & 0.907 \\
\hline 25243 & State highway & Lake & 34 & 0.935 & 67 & 0.972 \\
\hline 30967 & Principal arterial & Portage & 72 & 1.082 & 75 & 0.975 \\
\hline 57377 & Interstate & Summit & 62 & 0.890 & 82 & 0.870 \\
\hline 71877 & Interstate & Summit & 42 & 0.868 & 72 & 0.870 \\
\hline 76877 & Interstate & Summit & 75 & 0.874 & 82 & 0.876 \\
\hline 75777 & Interstate & Summit & 32 & 0.871 & 81 & 0.866 \\
\hline 75877 & Interstate & Summit & 37 & 0.865 & 84 & 0.890 \\
\hline 76677 & Principal arterial & Medina & 57 & 1.014 & 79 & 0.918 \\
\hline 76777 & State highway & Summit & 42 & 0.916 & 76 & 0.982 \\
\hline 92218 & Interstate & Cuyahoga & 35 & 0.879 & 70 & 0.892 \\
\hline 92318 & Interstate & Cuyahoga & 92 & 0.861 & 82 & 0.894 \\
\hline 92518 & Interstate & Cuyahoga & 102 & 0.834 & 34 & 0.824 \\
\hline 92818 & Interstate & Cuyahoga & 129 & 0.846 & 100 & 0.907 \\
\hline 93218 & State highway & Cuyahoga & 92 & 0.833 & 86 & 0.895 \\
\hline 93418 & State highway & Cuyahoga & 109 & 0.930 & 84 & 0.923 \\
\hline 94118 & State highway & Cuyahoga & 93 & 0.926 & 81 & 0.888 \\
\hline 97647 & Interstate & Lorain & 40 & 0.854 & 72 & 0.879 \\
\hline 99752 & Interstate & Medina & 57 & 0.911 & 72 & 0.868 \\
\hline 115618 & Interstate & Cuyahoga & 78 & 0.862 & 72 & 0.880 \\
\hline 121418 & Interstate & Cuyahoga & 32 & 0.913 & 70 & 0.910 \\
\hline All & & & 1505 & 0.894 & 1734 & 0.900 \\
\hline
\end{tabular}

from event to event and location to location (Niziol et al. 1995), and these factors may explain some variation in rates as well.

\subsection{Time of day}

We then examined trends in TDRs with time of day. Previous research by Al Hassan and Barker (1999), Datla and Sharma (2008) and Cools et al. (2010) suggested that traffic volume is most sensitive to inclement weather on weekends, when cancellable leisure trips are common. We expect time of day to have a similar effect on TDRs, perhaps with differences between weekdays and weekends. Figure 3 shows mean TDRs aggregated every $2 \mathrm{~h}$ of the day during the 25 selected snowfall events, on both weekdays and weekends. In Table 2, we show the results of a two-tailed Wilcoxon rank-sum test of the differences in weekday and weekend TDRs for five time periods.

On weekdays, traffic volume tends to be most susceptible to snowfall between $10 \mathrm{AM}$ and 2 PM local time, with mean DTRs at 0.8 , or volumes that are about $20 \%$ lower than during control periods. These midday TDRs are lower than the mean TDRs during 
Fig. 2 Boxplots of TDRs during lake-effect and synoptic-scale snow
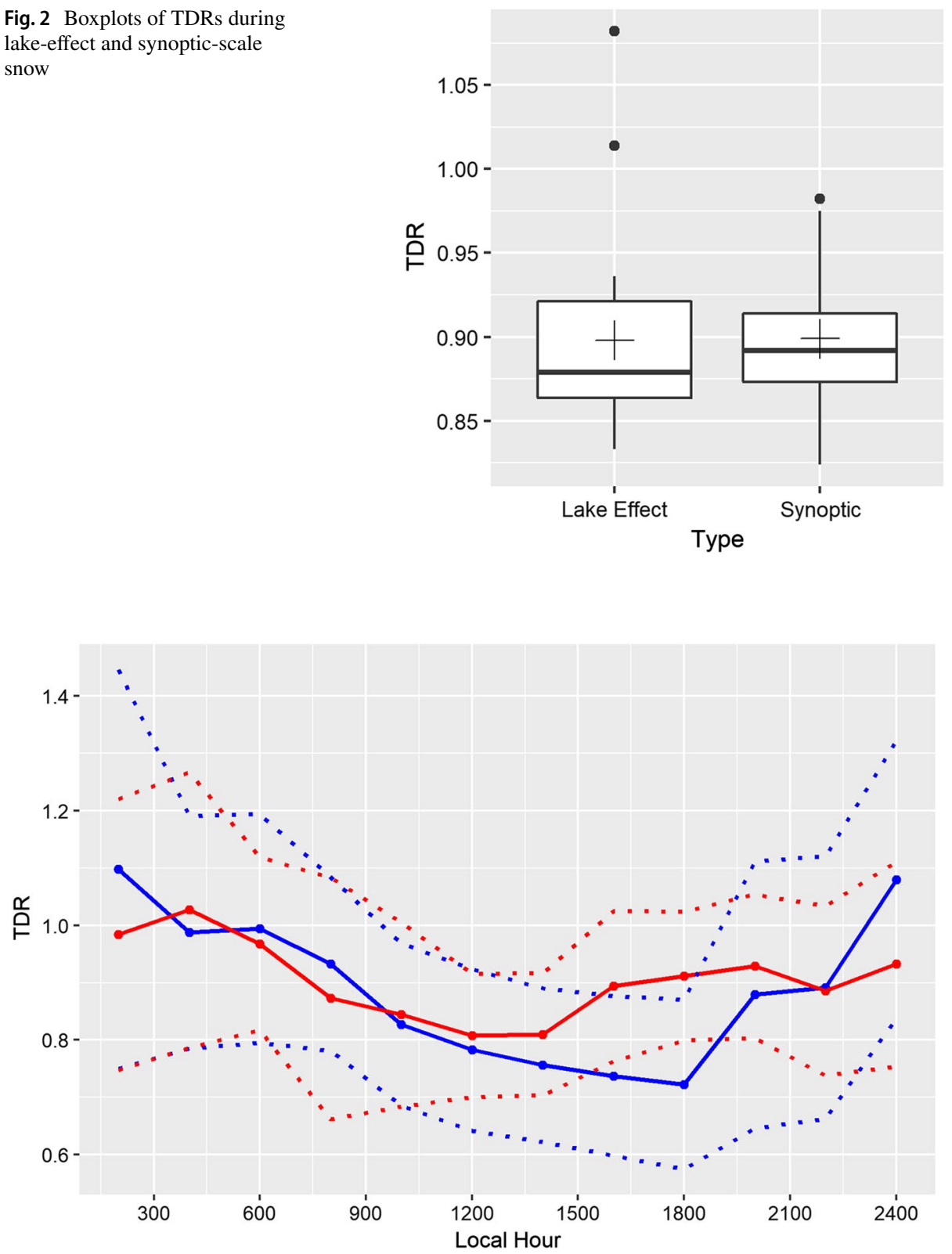

Fig. 3 Bi-hourly mean DTRs (solid lines) on weekdays (red) and weekends (blue), \pm one standard deviation (dotted lines)

traditional "rush hour" periods. This finding suggests that a driver who is commuting to and from work in the early morning or late afternoon is less likely to cancel their trip during snowfall than a driver who is making a midday trip that may or may not be workrelated. Northeast Ohio is climatologically very snowy, so employees are still likely to 
Table 2 TDRs during five time periods on weekdays and weekends, with a Wilcoxon ranked sum test for a difference between weekdays and weekends

\begin{tabular}{llllll}
\hline Time period & $\begin{array}{l}\text { Weekday } \\
\text { mean TDR }\end{array}$ & $\begin{array}{l}\text { Weekday stand- } \\
\text { ard deviation }\end{array}$ & $\begin{array}{l}\text { Weekend } \\
\text { mean TDR }\end{array}$ & Weekend SD & $\begin{array}{l}\text { Two-tailed } \\
\text { Wilcoxon } \\
\text { statistic }\end{array}$ \\
\hline $\begin{array}{l}\text { Overnight } \\
\text { 0000-0600 EST }\end{array}$ & 0.992 & 0.216 & 1.005 & 0.224 & $\begin{array}{l}W=81,643 \\
p=0.414\end{array}$ \\
$\begin{array}{l}\text { Morning } \\
\text { 0600-1000 EST }\end{array}$ & 0.857 & 0.184 & 0.885 & 0.156 & $\begin{array}{l}W=71,912 \\
p=0.063 \\
\text { Midday }\end{array}$ \\
$\begin{array}{l}\text { 1000-1400 EST } \\
\text { Afternoon }\end{array}$ & 0.808 & 0.107 & 0.770 & 0.138 & $\begin{array}{l}\boldsymbol{W}=\mathbf{6 8 , 5 0 6} \\
\boldsymbol{p}=\boldsymbol{0 . 0 0 1} \\
\text { 1400-1800 EST }\end{array}$ \\
$\begin{array}{l}\text { Evening } \\
\text { 1800-2400 EST }\end{array}$ & 0.915 & 0.125 & 0.729 & 0.144 & $\begin{array}{l}\boldsymbol{W}=\mathbf{1 8 , 9 6 9} \\
\boldsymbol{p}<\boldsymbol{0 . 0 0 1} \\
\boldsymbol{W}=\mathbf{1 6 0 , 4 5 0} \\
\boldsymbol{p}=\mathbf{0 . 0 1 3}\end{array}$ \\
\hline
\end{tabular}

Bolditalic values are represents the statistically significant at the 0.05 level

be expected to be at work regardless of whether or not snow is falling. This, we posit, is why morning and afternoon rush hour rates are higher than midday rates.

On weekends, traffic volumes differ from the bimodal rush hour trends in volume. Weekend TDRs in Fig. 3 are the lowest in the late afternoon, and the Wilcoxon test statistic between afternoon TDRs on weekdays and on weekends is statistically significant. Drivers are likely forgoing weekend evening leisure trips that they would have taken during fair driving conditions.

TDRs during overnight hours are near 1.0, indicating that traffic volume at these times is not sensitive to falling snow. We suggest two possible reasons for this. The first is that volume during overnight hours is low even during fair conditions, so drivers may be less concerned about multiple-vehicle accidents. The second is that drivers at these hours may be operating on tight deadlines and may not have the flexibility to alter their schedules for inclement weather. Truck traffic, which is often tightly scheduled, comprises a greater proportion of volume during snow events than during control periods (Call 2011). While we did not have available data on vehicle types, we surmise that this is an underlying factor for volumes near 1.0 during snow events at late-night hours. Variance is high at these times because how TDRs were calculated: Traffic volume is the lowest during overnight hours, and we used control period volume as the denominator in calculating TDRs. However, the trend in Fig. 3 is generally smooth, and we expect that the diurnal pattern it presents is robust.

\subsection{Summary of findings}

We found that well-sampled counters in northeast Ohio exhibited decreases in traffic volume by about $10 \%$ during selected snow events. Contrary to our hypothesis, there was no evidence to suggest that TDRs during lake-effect snow were higher than TDRs during synoptic-scale snow. There was substantial variation between counters and between snow types that may be attributed to several factors, including geographic location, road type and usage, snowfall intensity and time of observation. We did not have sufficient data to 
examine differences in TDRs between road types, but we did examine how TDRs varied with time of day and day of week.

TDRs were the highest during overnight hours on both weekdays and weekends. This is likely because trips that are made at these times are rarely cancellable, such as those undertaken by long-distance truck drivers, who make up a greater proportion of vehicles during snow events (Call 2011). During weekdays, TDRs are the lowest during the midday, at about 0.8. During rush hour periods, DTRs are at about 0.9 , higher than during the midday lunch hour. Most commuters are likely still expected to drive to and from work, even when it is snowing. On weekends, DTRs are the lowest in the late afternoon, perhaps because evening plans are usually for leisure and easily canceled. Weekday and weekend rates were significantly different between the hours of 1000 AM and 2400 PM local time, with weekends having lower rates and greater variance at these times.

\section{Conclusions}

Many factors affect traffic volume at any given location at any given hour. If differences in TDRs between synoptic and lake-effect events due to driver anticipation of weather conditions exist, they are probably washed out by other factors not accounted for in this study. Surveys on trip planning and driver behavior may shed light on how likely drivers are to cancel or continue their trips during various weather forecasts and conditions. Individual driver characteristics may also play a role: Someone with experience driving in snow may be less likely to be dissuaded from driving, and we expect that results of similar studies would vary depending on study area. Future research that examines snowfall intensity on traffic volume may also help account for some of this variation in traffic rates.

Our findings relating traffic volume during snowfall to times of day and days of the week are consistent with Al Hassan and Barker (1999), Datla and Sharma (2008) and Cools et al. (2010) in that volumes are most sensitive to snowfall when leisure trips are most common, such as weekend evenings and weekday lunch hours. While volumes during snowy rush hour periods are about $10 \%$ lower than control periods, workday commutes are less cancellable, and thus rates are higher at this time than on weekends. High traffic volumes at these times of day during inclement conditions could lead to elevated crash risk, as found by Call et al. (2019). Further examination of the relationship between volume, crash risk and weather could account differences in road and vehicle types, study regions and meteorological conditions such as snowfall intensity and visibility.

\section{References}

Abdel-Aty M, Pemmanaboina R (2006) Calibrating a real-time traffic crash-prediction model using archived weather and ITS traffic data. IEEE Trans Intell Transp Syst 7:167-174

Al Hassan Y, Barker D (1999) The impact of unseasonable or extreme weather on traffic activity within Lothian region, Scotland. J Transp Geogr 7:209-213

Andrey J (2010) Long-term trends in weather-related crash risks. J Transp Geogr 18:247-258

Andrey J, Mills B, Leahy M, Suggett J (2003) Weather as a chronic hazard for road transportation in Canadian cities. Nat Hazards 28:319-343

Barjenbruch K, Werner C, Graham R, Opperman C, Blackwelder G, Williams J, Merrill G, Jensen S, Connolly J (2016) Drivers' awareness of and response to two significant winter storms impacting a metropolitan area in the Intermountain West: implications for improving traffic flow in inclement weather. Weather Clim Soc 8:475-491 
Bates G, Giorgi F, Hostetler S (1993) Toward the simulation of the effects of the Great Lakes on regional climate. Mon Weather Rev 121:1373-1387

Baxter M, Graves C, Moore J (2005) A climatology of snow-to-liquid ratio for the contiguous United States. Weather Forecast 20:729-744

Black A, Mote T (2015) Effects of winter precipitation on automobile collisions, injuries and fatalities in the United States. J Transp Geogr 48:165-175

Call D (2011) The effect of snow on traffic counts in western New York State. Weather Clim Soc 3:71-75

Call D, Wilson C, Shourd K (2018) Hazardous weather conditions and multiple-vehicle chain-reaction crashes in the United States. Meteorol Appl 24:466-471

Call D, Medina R, Black A (2019) Causes of weather-related crashes in Salt Lake County, Utah. Prof Geogr 2:253-264

Changnon S, Changnon D, Karl T (2006) Temporal and spatial characteristics of snowstorms in the Contiguous United States. J Appl Meteorol Climatol 45:1141-1155

Cools M, Moons E, Wets G (2010) Assessing the impact of weather on traffic intensity. Weather Clim Soc 2:60-68

Crevier L-P, Delage Y (2001) METRo: a new model for road-condition forecasting in Canada. J Appl Meteorol Climatol 40:2026-2037

Datla S, Sharma S (2008) Impact of cold and snow on temporal and spatial variations of highway traffic volumes. J Transp Geogr 16:358-372

Eisenberg D, Warner K (2005) Effects of snowfalls on motor vehicle collisions, injuries, and fatalities. Am J Public Health 95:120-124

Ellis A, Leathers D (1996) A synoptics climatological approach to the analysis of lake-effect snowfall: potential forecasting applications. Weather Forecast 11:216-229

ESRI (2014) ArcGIS Desktop: Release 10.3. Environmental Research Systems Institute, Redlands, CA

Federal Highway Administration (2015) How do weather events impact roads? U.S. Department of Transportation. http://www.ops.fhwa.dot.gov/weather/q1_roadimpact.htm. Accessed 30 Aug 2019

Jiusto J, Weickmann H (1973) Types of snowfall. Bull Am Meteorol Soc 54:1148-1162

Kilpelainen M, Summala H (2007) Effects of weather and weather forecasts on driver behavior. Transp Res Part F Traffic Psychol Behav 10:288-299

Lake-effect snow leads to 40-vehicle crash on Kennedy, 12 hospitalized (2015). Chicago Tribune. http:// www.chicagotribune.com/news/local/breaking/chi-chicago-weather-forecast-20150215-story.html. 15 Feb 2015

Maze T, Agarwal M, Burchett G (2006) Whether weather matters to traffic demand, traffic safety, and traffic operations and flow. Transportation Research Record: Journal of the Transportation Research Board 1948:170-176

Medina R, Cervone G, Waters N (2017) Characterizing and predicting traffic accidents in extreme weather environments. Prof Geogr 69:126-137

Mills B, Andrey J, Hambly D (2011) Analysis of precipitation-related motor vehicle collision and injury risk using insurance and police record information for Winnipeg, Canada. J Saf Res 42:383-390

Niziol T (1987) Operational forecasting of lake effect snowfall in western and central New York. Weather Forecast 2:310-321

Niziol T, Snyder W, Waldstreicher J (1995) Winter weather forecasting throughout the Eastern United States. Part IV: lake effect snow. Weather Forecast 10:61-77

Roh H, Sharma S, Sahu P, Datla S (2015) Analysis and modeling of highway truck traffic volume variations during severe winter weather conditions in Canada. J Mod Transp 23:228-239

Rutty M, Andrey J (2014) Weather forecast use for winter recreation. Weather Clim Soc 6:293-306

Schmidlin T, Edgell D, Delaney M (1992) Design ground loads for Ohio. J Appl Meteorol Climatol 31:622-627

Three people dead in massive I-94 pileup (2014). NBC Chicago. http://www.nbcchicago.com/traffic/transit/ Crash-Michigan-City-7-Semis-241709461.html. 23 Jan 2014

Zhang S, Wang H, Liu X, Quan W (2013) Dynamic impact of meteorological factors on freeway free-flow volume and speed in Yanbian. Procedia Soc Behav Sci 96:2667-2675

Publisher's Note Springer Nature remains neutral with regard to jurisdictional claims in published maps and institutional affiliations. 